\title{
IMAGENS AVERSIVAS VEICULAdAS NOS MAÇOS DE CIGARROS: SigNifiCAdOS ATRIBUÍDOS POR UNIVERSITÁRIOS DA ÁREA DA SAÚDE DE UMA UNIVERSIDADE PÚBLICA ESTATAL
}

\section{Amanda Sena de Souza'; Claudinei José Gomes Campos ${ }^{2}$}

Este é um estudo de caso, qualitativo, que pretendeu analisar quais os significados atribuídos por estudantes universitários tabagistas, na área de saúde, face às propagandas de imagens aversivas, estampadas nas embalagens dos produtos do tabaco e as influências no seu comportamento de fumar. Utilizou-se apresentação visual das figuras junto a uma entrevista com questões semiestruturadas, aplicada a dez estudantes da área de saúde. Os dados foram submetidos à análise de conteúdo temática. Conclui-se que o conhecimento cognitivo não garante hábito saudável e há dissociação entre as imagens aversivas, veiculadas nos maços de cigarro, e seu conteúdo, não cumprindo integralmente sua intencionalidade.

Descritores: Tabagismo; Estudantes de Ciências da Saúde; Propaganda.

\section{Aversive images ADVERTIZed On Cigarette PACKAges: The MEANings that} \section{ASSIGNED BY STUDENTS OF A STATE UNIVERSITY IN THE HEALTH AREA}

This qualitative case study was performed with the purpose to analyze the meanings that smoking university students in the health area assign to advertisement using aversive images stamped on tobacco products and the effects on their smoking behavior. A visual presentation of the images was used along with an interview using semi-structured questions applied to ten students in the health area. The data was submitted to thematic content analysis. In conclusion, cognitive behavior does not guarantee a healthy behavior and there is dissociation between the aversive images advertized on cigarette packages and its contents, thus it does not comply integrally with its purpose.

Descriptors: Smoking; Students, Health Occupations; Propaganda.

\footnotetext{
1-Enfermeira, Graduada pelo Departamento de Enfermagem, Faculdade de Ciências Médicas, Universidade Estadual de Campinas, SP, Brasil. Bolsista Pibic-SAE. E-mail: amanda_sena22@yahoo.com.br.

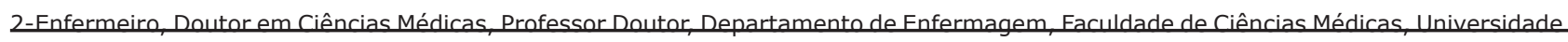
Estadual de Campinas. SP, Brasil. Líder do Núcleo de Pesquisa e Estudos Qualitativos em Saúde (Nupeqs). Pesquisador do Núcleo de Pesquisa em Psicanálise, Enfermagem e Saúde Mental (Nuppesm) e do Laboratório de Pesquisa Clínico-Qualitativa (LPCQ) da mesma instituição. E-mail: cjcampos@fcm.unicamp.br

Endereço para Correspondência:

Claudinei José Gmoes Campos

Alameda Cantanhede, 165

CEP: $13.342-410$

Indaituba, SP, Brasil

E-mail: cjcampos@fcm.unicamp.br
} 


\section{IMÁGENES AVERSIVAS VEHICULIZADAS EN PAQUETES DE CIGARRILLOS: SIGNIFICADOS ATRIBUIDOS POR UNIVERSITARIOS DEL ÁREA DE SALUD DE UNA UNIVERSIDAD PÚBLICA ESTATAL}

Estudio de caso cualitativo que pretendió analizar cuáles son los significados atribuidos por estudiantes universitarios tabaquistas en el área de salud frente a la propaganda de imágenes aversivas estampadas en los embalajes de los productos del tabaco y las influencias en su comportamiento como fumadores. Se utilizó la presentación visual de las figuras junto a una entrevista de preguntas semiestructuradas, aplicada a diez estudiantes del área de la salud. Los datos fueron sometidos a análisis de contenido temático. Concluimos en que el saber cognitivo no garantiza hábitos saludables, hay una disociación entre las imágenes aversivas vehiculizadas en los paquetes de cigarrillos y su contenido, no cumpliéndose integralmente con su intencionalidad.

Descriptores: Tabaquismo; Estudiantes del Área de la Salud; Propaganda. 


\section{Introdução}

O tabagismo é um dos maiores desafios para a saúde pública na atualidade, ocorrendo cerca de 5 milhões de mortes por ano (6 mortes por segundo) em todo o mundo, em torno de 200 mil mortes no Brasil, devido a doenças causadas em decorrência desse hábito ${ }^{(1-2)}$.

Mortes por doenças causadas pelo tabagismo são evitáveis, assim como mortes causadas pela utilização de outras substâncias psicoativas, e, ainda assim, dessas causas evitáveis, é a que mais mata em países desenvolvidos ${ }^{(1)}$.

Mesmo entre os médicos, os conhecimentos sobre a dependência de nicotina e técnicas de cessação de fumar ainda são iniciais, causando, aparentemente, dificuldades ainda maiores para o controle do tabagismo ${ }^{(3)}$. Também, entre estudantes da área da saúde, do curso de enfermagem mais especificamente, encontra-se prevalência do hábito do tabagismo de $15 \%{ }^{(4)}$, demonstrando que, mesmo entre indivíduos que supostamente têm informações sobre o tabagismo, o hábito ainda existe, proporcionando indícios de que o hábito de fumar e sua cessação estão além do puro saber e/ou ato cognitivo.

O tabagismo, socialmente, também é doença altamente influenciada pela publicidade, relacionada a interesses econômicos que utilizam estratégias diversas e complexas para levar a tal ato ${ }^{(5)}$. Essa dependência pode ser combatida principalmente com difusão ampla e constante de seus malefícios e dos impactos trazidos por esses ao indivíduo e à sociedade, com processo educativo de longo prazo que tenha aspecto preventivo ${ }^{(6)}$.

$O$ hábito de fumar vem sendo combatido pela Organização Mundial de Saúde (OMS), pelas propostas para o controle do tabagismo como, por exemplo, a recomendação aos governos de todos os países para que procurem realizar plano nacional de atuação, que desenvolva ações legislativas, determinando a colocação de advertências impactantes e variadas nos maços de cigarros $^{(3)}$.

O Brasil, seguindo a orientação da OMS, tem, desde 1987, um plano de ação onde o governo adotou medidas de controle do tabagismo e delegou ao Instituto Nacional de Câncer (Inca) a responsabilidade para o seu desenvolvimento. Ações como essa do governo brasileiro são necessárias, já que um terço da população brasileira adulta fuma, sendo 11,2 milhões mulheres e 16,7 milhões homens $^{(2)}$.

As promoções de estratégias antitabagistas, realizadas pela OMS e pelo governo brasileiro, são do tipo fiscalizador e educativo, entre essas, aquelas que têm maior destaque são as ações educativas pontuais com o objetivo de sensibilizar e informar a comunidade por meio de campanhas ${ }^{(3)}$.

O Brasil tem uma das mais estruturadas legislações do mundo para controle do tabaco, mas ainda enfrenta grandes desafios contra indústrias do fumo. Além da proibição, a publicidade do cigarro em 2000 e muitas outras medidas tomadas pelo governo, fazendo parte do Programa Nacional de Controle do Tabagismo (PNCT). Desde fevereiro de 2002, foram implementadas, nos maços de cigarros, imagens aversivas sobre o consumo de cigarro, levando essas indústrias a procurar novos métodos para incentivar o fumo e a procurar, nas leis, pontos que apresentem possibilidade de interpretações dúbias, para que possam voltar a fazer tais propagandas ${ }^{(5)}$.

Aindústria tabagista, na busca desses métodos, procura explorar as vulnerabilidades individuais na tentativa de induzir crianças e adolescentes a utilizarem, precocemente, o tabaco, e as vulnerabilidades coletivas, tentando impedir a disseminação do conhecimento científico sobre os males do cigarro ${ }^{(5)}$.

Há, também, dentro dessas tentativas, desvio de responsabilidade do tabagismo da indústria para o indivíduo fumante, que, agora, com mensagens de aviso nos rótulos e outras ações, é responsável por aceitar estar fumando, o que não é totalmente falso, mas parece deslocar de certa forma a responsabilização das indústrias ${ }^{(3)}$.

Para maior eficiência dessas advertências, foi descrito que elas devem ser: diretamente aplicáveis ao consumidor, explícitas e específicas, trocadas frequentemente, evitando que o público se acostume com elas e pare, então, de prestar atenção, escritas em letras grandes e em cores contrastantes $^{(7)}$. Também se fala da utilização de frases com palavras mais impactantes, com maior apelo à saúde do consumidor, como morte e câncer, para que possa produzir maior eficácia ${ }^{(7)}$.

Em abril de 2002, o Datafolha Instituto de Pesquisa encontrou, em sua pesquisa, que $76 \%$ dos brasileiros são a favor que embalagens de cigarros tragam imagens que ilustrem males provocados pelo fumo e, ainda, que $67 \%$ dos fumantes que viram as imagens afirmam terem sentido vontade de parar de fumar e, em dezembro desse mesmo ano, o serviço Disque Pare de Fumar, do Ministério da Saúde, revelou, em pesquisa realizada com 89.305 pessoas, que $62,67 \%$ consideram as imagens um ótimo serviço prestado à comunidade ${ }^{(8)}$.

A implantação de imagens aversivas, então, é uma das medidas mais evidentes para a população em geral, juntamente com as advertências escritas, tanto para o conhecimento de consumidores quanto para não consumidores de cigarro, sobre os malefícios causados pelo mesmo e se verifica importância estatística da população na compreensão de seu impacto.

Nota-se, também, a disseminação do hábito de fumar entre estudantes universitários de diversas áreas e, especificamente, entre estudantes da área de saúde, demonstrando que esse ato não é exercido somente por indivíduos que, formalmente, não apresentam em sua formação acadêmica conteúdos curriculares referentes aos malefícios decorrentes do tabagismo.

Assim, este trabalho teve o objetivo de analisar as características e significados atribuídos por estudantes universitários tabagistas, da área de saúde, mediante as imagens e mensagens aversivas, estampadas no verso dos maços de cigarro, e sua consequente influência sobre esse comportamento e hábitos de fumar.

\section{Percurso Metodológico}

$\mathrm{Na}$ realização desta pesquisa, foi utilizada a 
metodologia qualitativa, especificamente o estudo de caso, constituindo-se em um método no qual há apreciação de um caso, seja ele simples e específico, ou complexo e abstrato. $\mathrm{O}$ caso pode ser similar a outros, ao mesmo tempo distinto, por ter implicação própria e singularidade ${ }^{(9)}$.

A população escolhida para execução da pesquisa foi a de alunos fumantes de três cursos superiores (enfermagem, medicina e fonoaudiologia) da Faculdade de Ciências Médicas (FCM) da Universidade Estadual de Campinas (Unicamp).

A escolha desse grupo partiu do pressuposto de que esses alunos tinham algum conhecimento científico sobre os efeitos causados pelo tabaco e, também, por essas pessoas tornarem-se, futuramente, cuidadores de outras, com doenças causadas ou não pelo fumo. Outra justificativa para escolha de tal população foi o caráter paradoxal entre a questão dos conhecimentos científicos adquiridos nos estudos sobre os efeitos maléficos do tabaco e o próprio ato de fumar desses estudantes universitários.

A amostragem foi constituída por intencionalidade, perfazendo o total de dez indivíduos.

Na coleta de dados, foi utilizada a técnica de entrevista com roteiro semiestruturado. .As entrevistas foram realizadas nas dependências da FCM, sendo oferecida privacidade adequada para condução das mesmas.

Em determinado momento previsto, durante a entrevista, foram apresentadas ao entrevistado cerca de cinco das dez imagens veiculadas nos versos dos maços de cigarro, escolhidas aleatoriamente, e as outras cinco imagens foram citadas a fim de relembrar o entrevistado. Após a apresentação das imagens, foram realizadas perguntas contidas no roteiro que versavam sobre hábitos tabagistas dos sujeitos e a opinião sobre o uso das imagens e o impacto causado no seu comportamento tabagista.

$\mathrm{O}$ projeto de pesquisa foi aprovado pelo Comitê de Ética em Pesquisa da Instituição, sob nº642/2007. Todos os sujeitos que compuseram a amostra leram e assinaram o termo de consentimento livre e esclarecido (TCLE), recebendo uma via assinada.

$\mathrm{Na}$ análise de dados, utilizou-se o método de análise de conteúdo temático ${ }^{(10)}$. Inicialmente, foram feitas várias leituras do material coletado, selecionando as unidades de análise que, posteriormente, foram agrupadas em categorias, analisadas e discutidas sob vertente teórica cognitiva comportamental.

\section{Resultados e discussão}

\section{Descrição dos sujeitos da pesquisa}

Quatro sujeitos da amostra cursavam enfermagem, quatro cursavam medicina e dois, fonoaudiologia. $\mathrm{O}$ ingresso à faculdade ocorreu entre os anos 2005 e 2008. A faixa etária variou de 20 a 28 anos, com média de 22,4 anos, sendo entrevistados nove sujeitos do sexo feminino e um do sexo masculino. O início do hábito de fumar dos sujeitos dessa amostra apresentou preponderância na adolescência, entre as idades de 12 e 18 anos, com média de 13,3 anos, fato amplamente encontrado na literatura ${ }^{(11-12)}$. O número de cigarros fumados por dia variou de 3 a 40, sendo que fatores como o estresse, ansiedade e eventos sociais (festas) determinavam maior número de cigarros consumidos diariamente. A fase de menor consumo situou-se nos demais momentos rotineiros desses sujeitos, verificando média de 9,7 cigarros, nesses períodos habituais. Sobre o período do dia em que mais fumam, seis pessoas afirmaram ser o período noturno, duas o período da tarde, uma o período da manhã e uma durante festas, quando está consumindo bebidas alcoólicas.

\section{Categorias}

Com o intuito de manter coerência na apresentação e discussão dos dados, optou-se por discorrer inicialmente a categoria que apresenta visão mais ampla sobre o tema estudado e os seus efeitos, a fim de contextualizar nas categorias subsequentes a discussão sobre o impacto que as imagens aversivas, veiculadas nos maços de cigarros, têm sobre o indivíduo.

\section{A preponderância da dependência sobre a crítica}

A dependência física e psicológica, causada pela nicotina, envolve diversos fatores como os biológicos (inter-relações farmacológicas), os adquiridos, os de personalidade e de condições sociais. Justificativas dadas para o consumo dessa droga são efeitos como prazer, aumento da vigília, diminuição da ansiedade ou estresse, diminuição da fome e perda de peso corporal ${ }^{(13)}$. Essa dependência leva as pessoas a usarem o tabaco, mesmo sabendo dos riscos à saúde.

Eu sei que faz mal, mas eu não consigo parar (E1).

... eu não sei se eu estou preparada para largar (E5).

Embora os sujeitos da pesquisa tenham demonstrado conhecimento cognitivo face aos males causados pelo tabagismo, como já descrito, a dependência se sobrepõe à crítica dessas pessoas, fazendo com que elas mantenham o hábito de fumar.

A dependência nicotínica envolve reações físicas e psicológicas, onde as psicológicas exigem o uso da substância para que a pessoa tenha a sensação de máximo funcionamento corporal e de bem-estar, sendo difícil a cessação do vício diante dessa dependência ${ }^{(14)}$.

... sou de achar que nunca nada vai acontecer comigo (E2).

Também surgiram questões de não haver preocupação, por parte dos fumantes, quanto à ocorrência de alguma doença causada pelo tabagismo, pois eles acreditam não serem passíveis de contraírem doença, pelo menos na atualidade, mostrando possível preocupação apenas com o futuro. Isso pode ocorrer pelo fato de o fumante não querer enfrentar a realidade, pois é preferível ignorar os fatos, aproveitar os efeitos prazerosos e pensar que esses danos podem não lhe ocorrer no momento, acreditando que, futuramente, quando seria mais provável ocorrer algo, já teria deixado de fumar, evitando alguma doença.

Eu acho que as campanhas antitabagismo que mexem com isso elas erram, porque são consequências a muito longo prazo. Então a gente tende a não se preocupar agora, (...) dai a 
gente sempre fala' 'ah, um dia eu vou parar e não vai acontecer nada'(E6).

Nota-se, na fala de E6, uma crítica às campanhas publicitárias antitabágicas, segundo o sujeito, deixando subliminarmente entendido que os efeitos maléficos do cigarro só ocorrem em longo prazo, ficando, assim, a falsa sensação de que a nicotina tem efeito danoso apenas com seu uso constante e duradouro. Tal afirmação pode levar à inferência de que as campanhas estariam levando as pessoas a terem noção errônea sobre os verdadeiros malefícios que o ato de fumar pode apresentar, tanto no presente como no futuro, para a própria pessoa e as demais que a cercam.

Indiferença em relação às imagens aversivas estampadas nos maços de cigarro

Quando questionados sobre levarem em consideração a presença das imagens no maço de cigarros, no ato da compra, encontraram-se significativos relatos de que havia indiferença em relação à presença das imagens estampadas nos maços, como se pode observar pelos relatos abaixo.

Eu não vou parar de fumar por causa da figura (E1).

Não muito. (...) Olho como se fosse uma capa de revista, o que me chama atenção não é a capa, mas o que tem dentro (E4).

... quando eu paro pra pensar, não é por causa das imagens, é pela informação que eu tenho. As imagens pra mim não causam impacto nenhum (E6).

Há relatos na literatura de que as imagens contidas nos maços de cigarros reforçam o conhecimento e a dimensão dos riscos do tabagismo e elas, também, poderiam fazer com que o fumante refletisse cada vez que fosse acender um cigarro $^{(5)}$.

$\mathrm{O}$ fato de os sujeitos se sentirem indiferentes diante dessas imagens demonstra que não causam o impacto que deveriam. Percebe-se que, mesmo as imagens estando contidas nas embalagens, os fumantes relataram que, além de não observá-las no momento da compra, quando vão acender o cigarro, eles não terão necessariamente contato com a imagem, já que podem evitá-las, mesmo porque a face do maço que é aberta para retirar o cigarro não é a que contém a imagem. Além disso, foi citado que as imagens são repetitivas e, com isso, se tornam menos chocantes com o decorrer do tempo, fato corroborado na literatura ${ }^{(7)}$.

Eu sinceramente não sabia. Aí eu fui atrás (...). Eu vi uma pesquisa que diz que diminuiu o percentual, mas foi muito pouco. E depois de um tempo essas imagens começam a anestesiar a cabeça com essas imagens, você acha comum, ai os fumantes que pararam inicialmente com essas imagens, vão começar a voltar (E4).

Acho que, por exemplo, se eles começassem a diversificar agora, de novo, colocar novas fotos, não sei, poderia chocar de novo (E5).

Mesmo os entrevistados terem se mostrado, na maioria, indiferentes face às imagens, alguns relataram sobre amigos que têm visão diferente da deles e que chegam a pedir, no estabelecimento em que compram o cigarro, para que a embalagem seja trocada e também relatam piadas sobre as imagens como "sabor" do cigarro.

Quero o sabor rato e baratas (sobre imagem de rato e barata), esse dai eu falo que se eu fumo e quando tiver um rato ou uma barata dentro de mim eles vão morrer (E1).

$\mathrm{Na}$ verdade, essas imagens não surtem efeito nenhum, as pessoas até brincam com essas imagens, falando '(...) eu quero o de câncer, mas o de impotência não'(E9).

Tratando-se de população jovem, pode também ocorrer, por parte de alguns indivíduos, práticas de resistência, de oposição e de contestação a esses discursos oficiais divulgados. Entende-se que as pedagogias culturais fazem parte de território de lutas, onde sentidos e significados podem ser reelaborados, produzindo novas formas de identidades com o produto veiculado ${ }^{(15)}$.

Dissociação entre aparência simbólica e conteúdo do maço de cigarros

Parece mais fácil as pessoas associarem simbolicamente o cigarro a situações que causam prazer, do que fazerem a mesma associação com situações que lhes causam aversão ao uso do mesmo. Essa dissociação pode ser gerada pela angústia ou ansiedade causada pelo contato com imagens que lhe suscitam familiaridade com situações patológicas, vivenciadas pelos seres humanos. Ou seja, o sujeito prefere não relacionar o fator de promoção de prazer ou bem-estar pessoal, trazida pelo tabaco, daquele que o coloca em contato com uma realidade possível, a do sofrimento ocasionado por patologias extremamente graves.

Levo, ô loco! Eu não pego qualquer imagem não. Ah, eu não pego imagem de criancinha passando mal, imagem de aborto, Deus me livre! Eu chego lá e falo 'tia, me dá o que mata rato'(E3).

... eu tenho amigos que não gostam de ver, que colocam papel em cima, ou que pedem pra trocar, tem gente que não gosta (E1).

Percebe-se, em algumas falas, um conceito dissociativo, aqui tratado como mecanismo de defesa que diz respeito ao controle de informações capazes de provocar ansiedade ou sofrimento ${ }^{(16)}$.

Nota-se, também, que o ato de dissociar ou esconder as figuras, remete ao comportamento de evitação da incômoda realidade dos fatos. À medida que os sujeitos afastam, visual e psicologicamente, o mal-estar, causado pelas figuras estampadas nos maços de cigarros, assumem o consumo do produto embalado em sua dimensão prazerosa e livre de culpas.

\section{Controvérsias perante os impactos causados pelas imagens}

Duas perguntas contidas no questionário, a fim de esclarecer o que os próprios achavam sobre o impacto das imagens contidas nos maços, foram: o que você acha da utilização dessas imagens no combate ao tabagismo? e, em sua opinião, você acredita que essas imagens tenham algum efeito na ação contra o tabagismo para outros fumantes? Justifique. 
Quanto à primeira questão, em unanimidade, foi respondido que as imagens não surtem nenhum efeito como estímulo a parar de fumar para os próprios entrevistados.

Combate (...) Ah, pra mim não muito (E3).

... eu acho que, pelo menos pra mim, não tem como passar em branco. (...) (se tem efeito) Pra mim? Não, é o que eu falei, eu acho que já teve mais (E5).

... pra mim não, por que tem muita coisa aqui que eu já sabia que seria assim (E8).

Já na segunda questão, houve diversos pontos controversos, visto que responderam que as imagens podem ou não ter efeito, dependendo de fatores como: reflexão pessoal; ser ou não fumante, sendo que se relatou que, para os não fumantes, seria mais efetivo, pois eles poderiam olhar a imagem e refletir sobre o que pode ocorrer com eles, ter ou não acesso aos conhecimentos sobre os danos causados pelo tabagismo, pois, para aqueles que não têm essas informações, as imagens seriam mais efetivas, mesmo sendo dito que o acesso a essas informações é muito amplo, hoje em dia, que a pessoa teria algum tipo de conhecimento, entre outros aspectos.

Pode te alarmar e a pessoa parar pra pensar, mas ser o motivo principal pra pessoa parar de fumar, acho que não. (...) é à força de vontade (E2).

Eu acho que surte... às vezes a pessoa não tem nenhum tipo de informação (E8).

Mas quem já está fumando, sinceramente (...) só vai fazer diferença se algum desses danos reportados acontecerem com a pessoa (E4).

Quando ocorreu a fala de que as imagens não têm efeito para outros fumantes, a justificativa foi de que seria para aqueles que não tivessem acesso às informações, mas que, nos dias atuais, é muito difícil alguém não ter nenhum tipo de informação.

\section{Conclusões}

Existe, entre os sujeitos da pesquisa, conhecimento abrangente sobre danos causados pelo tabagismo, seja por meio da graduação em um curso da área da saúde, por interesse da própria pessoa ou por conhecimentos adquiridos ao longo da experiência de vida, mas que não garante a aquisição de comportamento saudável.

Os sujeitos utilizam a dissociação entre a aparência simbólica do maço de cigarros e o conteúdo propriamente dito como maneira de utilizarem o produto de forma prazerosa e livre de culpas. As imagens mostraram não possuir significação impactante sobre os fumantes, quando se pensa sobre a cessação do tabagismo, porém, ocorrendo relatos que as imagens poderiam ter efeito em outros fumantes.

Ainda que existam o conhecimento e a conscientização, o hábito de fumar ainda persiste entre os entrevistados, o que pode ocorrer por diversas razões, influenciadas por fatores fisiológicos, psicológicos, sociais ou outros.

Acredita-se que campanhas e mensagens, veiculadas por qualquer meio de comunicação, e que promovam sensibilização e conscientização dos fumantes ou potenciais consumidores desse produto, sejam de extrema importância. Da mesma maneira, sentiu-se, aqui, a necessidade de maior aproximação dos produtores dessas campanhas e mensagens aos consumidores do produto, com a finalidade de compreenderem melhor que aspectos psicológicos e que singularidades estão envolvidas na percepção desses à mensagem veiculada.

\section{Referências}

1. Menezes AMB. Diretrizes para Cessação do Tabagismo - Epidemiologia do tabagismo. J Brase Pneumol. 2004;30(Supl 2): 3-6

2. Ministério da Saúde (BR). Portal da Saúde. Dados e números do tabagismo no mundo e no Brasil [acesso 23 out 2006]. Disponível em: http://portal.saude.gov.br/ portal/saude/visualizar_texto.cfm? idtxt=13486

3. Cavalcante TM. O médico e suas representações sobre o tabagismo, fumante e cessação de fumar [dissertação]. Rio de Janeiro: Fundação Oswaldo Cruz. Escola Nacional de Saúde Pública; 2001.

4. Oguisso T, Seki LK. Prevalência do tabagismo entre estudantes de graduação da escola de enfermagem da Universidade de São Paulo. Rev Esc Enferm USP. 2001;35(1):19-27.

5. Cavalcante TM. O controle do tabagismo no Brasil: avanços e desafios. Rev Psiq Clín. 2005;32(5):283-300.

6. Marra ML. Comunicação e saúde - o tabagismo em pauta: Exame, Isto é Dinheiro, Vencer e Você S/A [dissertação]. São Paulo: Faculdade de Comunicação Social Cásper Líbero; 2007.

7. Vicent AL. Advertencias en las cajetillas de cigarrillos en América Latina y el Caribe. Bol Of Sanit Panam. 1993;114(6):492-501.

8. Datafolha Instituto de Pesquisa - Opinião pública [homepage na internet]. São Paulo: Datafolha Instituto de Pesquisa. $76 \%$ são a favor que embalagens de cigarros tragam imagens que ilustram males provocados pelo fumo [aproximadamente 3 telas]. [atualizado em: 21 abr 2002]; [acesso 6 maio 2008]. Disponível em: http://datafolha. folha.uol.com.br/po/fumo_21042002.shtml

9. Ludke M, André MEDA. Pesquisa em educação: abordagens qualitativas. São Paulo: EPU; 1986.

10. Campos CJG. Método de Análise de Conteúdo: ferramenta para a análise de dados qualitativos no campo da saúde. Rev Bras Enferm. 2004;57(5):611-4.

11. Segat FM, Santos RP, Guillande S, Pasqualotto AC, Benvegnú LA. Fatores de risco associados ao tabagismo em adolescentes. Adolesc Latinoam. 1998;1(3):163-9.

12. Matsumoto KS, Craveiro MF, Rocha PR, Lopes GT. O uso do tabaco entre os universitários de enfermagem da Universidade do estado do Rio de Janeiro (UERJ). SMAD, Rev Eletrônica Saúde Mental Álcool Drog. (Ed. port.). [online]. ago. 2005;1(2). [acesso 12 jan 2010]. Disponível em: http://pepsic.bvspsi.org.br/scielo.php?script $=$ sci_arttext\&pid=S180669762005000200006\&lng $=$ pt\&nrm $=$ iso $>$. ISSN 18066976. 
13. Saito MI. Adolescência Cultura e Vulnerabilidade e Risco. A Prevenção em Questão. In: Saito MI, Silva LEV. Adolescência Prevenção e Risco. São Paulo: Atheneu; 2001. p. 33-8.

14. Souza ALOP. O tabagismo e os programas de auxílio à cessação do fumar [dissertação]. Florianópolis: Universidade Federal de Santa Catarina; 2003

15. Renovato RD, Bagnato MHS, Missio L, Murback SESL, Cruz LP, Bassinello G AH. Significados e sentidos de saúde socializados por artefatos culturais: leituras das imagens de advertência nos maços de cigarro. Ciênc. saúde coletiva [Internet]. 2010 [acesso 2 fev 2010]; 14(Supl-1):1599-1608. Disponível em: http://www. scielo.br/scielo.php?script $=$ sci_arttext\&pid $=\mathrm{S} 1413$ 81232009000800033\&lng=pt. doi: $10.1590 / \mathrm{S} 1413-$ 81232009000800033.

16. Negro PJ Junior, Palladino-Negro P, Louzã MR. Dissociação e transtornos dissociativos: modelos teóricos. Rev Bras Psiquiatr. [Internet]. 1999 [acesso 18 março 2010]; 21(4):239-48. Disponível em: http:// www.scielo.br/scielo.php?script=sci_arttext\&pid=S15164461999000400014\&lng=en. doi: 10.1590/S151644461999000400014.

\section{Como citar este artigo:}

Souza AS, Campos CJG.. Imagens aversivas veiculadas nos maços de cigarros: Significados atribuídos por universitários da área da saúde de uma universidade pública estatal. SMAD, Rev. Eletrônica Saúde Mental Álcool Drog. (Ed. port.). jan-abr 2011 [acesso: ;7(1):38-44. Disponível em:
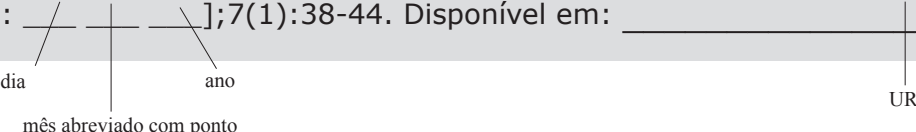

mês abreviado com ponto 